\title{
Electronic Computers - The Challenge to Management
}

\author{
This paper was first published in elektronische datenverarbeitung 1(1)1959:20-23.
}

\section{DOI 10.1007/s12599-008-0017-0}

\section{The Author \\ John Diebold \\ New York \\ USA}

This article is also available in German in print and via http://www.wirt schaftsinformatik.de: Diebold J (2008) Elektronische Computer - Eine Herausforderung für die Unternehmensleitung. WIRTSCHAFTSINFORMATIK. doi: 10.1007/11576-008-0123-0.

Although in the United States there are something in excess of 1,000 computers in actual operation in business and industry we feel that our record of accomplishment is far from brilliant. We in the States are beginning to take a critical look about us in this regard. We feel that it is not presumptuous to assume that Germany and the rest of Europe may well be able to learn something of value from the mistakes we have made. Therefore the purpose of this course is to present a critical analysis of U.S. experience in the business use of digital computers and other automatic data processing equipment.

Today in the United States we have a large number of splendid new machines as technically complex as any that man has ever built. But if the real facts be known, very few of them are being used in a way that even begins to exploit their full potentialities. In fact all but a tiny fraction are being used to do precisely what was done equally well and in many cases for far less cost by punched card machines. This is an almost unequalled example of sheer waste of a great business resource. It is something like as wasteful as mining a whole mountain of iron and then throwing away all but the low-grade ore.

These computers are being badly used because there is so little understanding of how they should be used and because of the widespread underestimation of the magnitude of the task of using them properly. Most managements have been too uncritical in accepting what they have been told are the chief facts about automation. Month in month out the businessman reads that the ultimate in automation is a computer, a fascinating, intricate machine that can do arithmetic at the speed of light. This machine, he is told, is the answer to the personnel manager's prayer because it never makes a mistake or gets a headache in the middle of the afternoon or leaves its department short of help because it has decided to get married.

$\mathrm{He}$ is seldom told that anything the machines may do to relieve the shortage of clerks is trivial compared with what they could do to improve the way his business runs. And he is seldom told that machines are the least important aspect of automation. He does not yet understand that a computer is not, by itself, automation, however big and fancy and expensive it may be, that it is nothing more than a tool, just as surely as a hammer or a wrench or a typewriter or an adding machine is a tool.

Companies tend to mechanize, via the high speed computer, activities that are currently handled quite well on punched card and similar small scale equipment. The result is that they waste a great deal of time and, more important, managerial and technical ability in converting from existing procedures to computers when they might make far better use of the computers to do things that have not been done. Typically, payroll is the first application while some future vague time is allocated to the use of the machine for handling operations research and other decision-making problems. More important the capacity of the new machines has not even begun to be used when they are given problems in a fragmented nature (such as payroll, receivables, production control, etc.). It is only by an integrated systems approach and the handling of many activities at once that the true value of the machines begins to be appreciated.

Automation in data processing means less drudgery for clerks but in its planning stages it means more work for management, more attention to management's specific task of creative organization. It means that a manager must take a new look at all activities in which data processing is involved and must see as a whole operations that have traditionally been broken down into many different departments. Automation in fact puts good management at a premium. There have been cases where the very effect of examining a company's operations with a view to the use of a computer has been so salutary that no computer has been needed. The novel co-ordination approach has itself been sufficient to point the way to reorganization without the use of machines at all. Management must solve certain fundamental problems of its own before it can expect a computer to solve further routine problems. It is just as easy, and usually much more expensive, to mismanage a computer as it is to mismanage people.

The problem of course is that the systems approach means a major effort and a long period of study before the machines can be applied. In America there is a current mania for having computers in the company. It is a great point of pride and a fine note to list in the annual report to shareholders. Using a computer to do precisely what is being done by other methods is the fastest way of getting the machine in.

Management is still pursuing the willo'-the-wisp of labor savings as the principal justification for the computer. In actual fact this has proved to be false. There are very few computers in the States that vaguely begin to pay for themselves in terms of labor savings. Moreover a computer is extremely costly in terms of the huge managerial and technical effort required to program machines and the sacrifice of time that occurs before the 


\section{Abstract \\ John Diebold \\ Electronic Computers - The Challenge to Management}

The potentialities of computers have not been fully exploited in the U.S. because management has underestimated the task of putting them to proper use. Management has believed that computers themselves are automation. But automation places a premium on good management. Without careful management planning, business resources are wasted in terms of managerial and technical time and abilities.

Since computers are capable of handling many tasks simultaneously, it is only by casting aside the departmental concept and substituting the integrated systems approach that the true value of these machines begins to be appreciated. Automatic data processing provides for the tighter control that is important in competitive markets.

The key to the whole problem of putting automation to work is education of personnel. Knowledge of equipment and techniques is not enough. Automation, by permitting handling of many jobs simultaneously, is in direct conflict with the concept of division of labor. The businessman, faced with wholesale reorganization of work, must train more basically and broadly. Current training for this field is largely dependent upon specialized courses offered by the manufactures of computers. The responsibility for training these people is largely that of private business, and it is a larger task than most managers realize. If a businessman is to feel confident that his company's data processing is not just a gamble, he must accept this new challenge to management.

Reprint of a paper from elektronische datenverarbeitung 1(1)1959:20-23.

Keywords: Automation, Automatic data processing, Electronic computers, Management, Education machine is allowed to operate on problems having a high yield.

The labor saving fixation raises another problem which can be serious. If in the end you are really not going to have very large labor saving it is fallacious to raise the human and social problems and the outcries that occur when there is talk of putting a machine into a business to replace clerks. If you don't make major cuts in personnel, for goodness sake don't talk beforehand as if you were going to.

We feel that this fact is of special significance to German and European business because your clerical costs are not nearly as much as ours and if the economic justification of the machine is going to have to come from improved efficiency and by sharpening up and by making more precise the tools of management, it is a very important fact for the German and European businessman to recognize from the start.

The very fact of automatic data processing is of increasing importance to companies dependent upon the new Western European common market for their trade area: (1) the emergence of the new common market requires peak efficiency, and (2) permits the efficient company to take full advantage of its increased competitive status. The expansion of the market area, the first emergence of a true mass market in Europe, is of very great importance and we feel one of the reasons our European training effort is very timely. The rational distribution of production facilities (with companies looking at themselves as vendors) as well as the distribution system can be aided enormously by the proper use of automatic data processing. Real cost factors will play a much more important role in the new customs union than they have in the past and the advantage will go to those who have tighter control of their business. Automatic Data Processing (ADP) provides for such tighter control.

There are some basic differences between German and European companies on the one hand and American companies on the other hand. In this particular area of automatic data processing, I would say the advantage is on the side of Europe - in very practical terms:

1. German and European businessmen are used to squeezing much more from their equipment in general than are Americans. (The U.S. has emerged from the war as a fat, rich country expressing many of the characteristics of the nouveau riche).

2. Americans are less concerned with refined uses of their automatic data processing equipment.

3. European businessmen take a more scientific approach to management.

4. You have far better basic education and training for your people. This is of major importance.

It is important that your managements recognize that they are going to have to take on a new people and to train people. They should not become preoccupied with equipment and techniques.

You must walk the fine line between taking an overall approach dominated by the systems concept and yet singling out a small enough chunk of the problem to get started in a practical manner and yet in a way that will be consistent with making a gradual expansion of these areas of work until the overall system is handled by the machine.

We feel that it is really much later than most people think in terms of time in which major efforts must be made to ensure the success of automatic data processing programs.

So far I have dealt mainly with management's task of organization for automatic data processing. But there is another, and most important, aspect of management's responsibility for automation which will occupy a large part of our time here this week. That is the education of personnel.

The changes involved in putting automation to work are such that training people is, I think, the key to the whole problem. Business and industry are going to have to take responsibility for the most colossal job of education they have ever faced. And it will not be so simple as training workers in specific skills, such as programming computers, although that is part of it. The practical problem business faces today, not in some vague tomorrow, is the problem of basic training and education of the men and women in business not just in how to work the machines but in how to use them to solve management problems.

The machines of automation are only symbols of the fundamental developments that are taking place in the way we organize our world. The training of management personnel must reflect this fact. But such education programs as have accompanied automation hardly even begin to reflect it because businessmen who under- 
stand this themselves are as rare as whooping cranes.

Preoccupation with hardware is by no means unique to automation. It was true of the first industrial revolution as well. The symbol of that great movement was power-driven machinery. But as Paul Mantoux points out in this excellent study "The Industrial Revolution in the Eighteenth Century”: “...the use of machinery itself, important as are its consequences, is only a secondary phenomenon."

It was the changes of human organization, in this case division of labor and the exchange of commodities, that were the revolution. Power-driven machinery was the tool that made the revolution possible and made it work.

To get some idea of the extent and depth of the changes that are starting to take place through automation, think for a moment of all that is implied in the concept of an integrated system of work, for example, a single computing machine capable of performing many operations at once. This beguilingly simple concept is revolutionary in its meaning and implies a fundamental change in the way we have been doing business for the last two hundred years. It is in direct conflict with the very concept of the division of labor, which has been the key to business organization from the time of Adam Smith's pin factory to today's jet engine production line.

The result is that offices, as well as factories, are organized by functions. Payroll preparation, billing, accounts payable, cost and financial accounting are handled by separate people or separate departments, and where they have been mechanized they are mechanized in the same way. Even the introduction of punched card machinery in the form of central processing units has not changed this organization. The same machines may be used to process all types of work, but the jobs are still run separately and are only related to one another in the most general way. The tabulating room, for instance, will make a payroll run, followed by a cost distribution run, then a payables run, each one handled as if it were an entirely separate job.

Automation and its related technology presents us with the means to build a machine system that can handle a great number of information-processing tasks simultaneously. For example, processing new orders, scheduling production, checking raw materials inventory, cost distribution and machine loading can all be handled as part of the same interrelated problem - which of course they are in the real world. What this means is that we now have the ability to organize our work in a closer relation to reality. We no longer need to make the organization of paper work as much or an abstraction from dayto-day happenings as it has always been.

In order to actually do this, however, the businessman is faced with a wholesale reorganization of work the likes of which he has never before even had to contemplate. If he uses the new machines of automation just to do more rapidly tomorrow that he is already doing today, he will not have come to grips with the problem; worse, he will have let slip the opportunity of his business lifetime.

At the start, and for quite a few more years, the practical solution to this problem is going to have to come from business itself. There is no hope, in the immediate future, that the buck can be passed along to the colleges and high schools, although in time, if business understands what its needs truly are and makes these needs known, the education system will begin to produce young men and women trained not just to use automation equipment but to understand the demands of automation.

But as things stand, the great bulk of the people who are going to be in on the crucial task of administering the conversion to automation, and those who are going to be living and working in a world at least partly automated, are men and women who have already completed their formal education and are now working in business and industry. The responsibility for training these people is lately that of private business, and the task is a far larger one than most managements as yet realize.

Current attempts at training in data processing depend largely on the courses in how to use the machines that equipment manufacturers give to their customer's personnel and on a few similar university extension programs. Such training is almost always tied to the machines of automation, and it is hardly adequate even to develop a proper understanding of their machines. It rarely begins to indicate the nature of the problem of how to apply them. Moreover, these schools are tied only to machines, which is bad enough, but to the machines of one particular manufacturer. Attending only one of these schools is something like expecting to learn about political science by spending a few weeks in the local Republican or Democratic ${ }^{1}$ headquarters.

What is needed is training that is more basic, broader in scope, more intensive, given in great depth. The success of a computer program depends only partly on adequate training in programming for those who will actually convert a business problem to machine instructions - a training problem that, in itself, requires many months of on-the-job instruction beyond the scant month or two in a manufacturer's school, if a prudent businessman is to feel confident that the success or failure of the entire program is not just a gamble. 